\title{
Traditional Herbal Formula Banhasasim-tang Exerts Anti-Inflammatory Effects in RAW 264.7 Macrophages and HaCaT Keratinocytes
}

\author{
Seong Eun Jin, ${ }^{1}$ Hye-Sun Lim, ${ }^{1,2}$ Yeji Kim, ${ }^{1}$ Chang-Seob Seo, ${ }^{1}$ Sae-Rom Yoo, ${ }^{1}$ \\ Hyeun-Kyoo Shin, ${ }^{1}$ and Soo-Jin Jeong ${ }^{1}$ \\ ${ }^{1}$ Herbal Medicine Formulation Research Group, Herbal Medicine Research Division, Korea Institute of Oriental Medicine, \\ Daejeon 305-811, Republic of Korea \\ ${ }^{2}$ Division of Allergy and Chronic Respiratory Diseases, Center for Biomedical Sciences, \\ Korea National Institute of Health, Chungcheongbuk-do 361-951, Republic of Korea
}

Correspondence should be addressed to Soo-Jin Jeong; sjijeong@kiom.re.kr

Received 16 December 2014; Revised 16 February 2015; Accepted 24 February 2015

Academic Editor: Ho Lin

Copyright (C) 2015 Seong Eun Jin et al. This is an open access article distributed under the Creative Commons Attribution License, which permits unrestricted use, distribution, and reproduction in any medium, provided the original work is properly cited.

\begin{abstract}
Banhasasim-tang (BHSST) is a Korean traditional herbal formula comprising eight medicinal herbs. The aim of the present study was to investigate the anti-inflammatory effect of BHSST using macrophage and keratinocyte cell lines. First, we evaluated the effects of BHSST on inflammatory mediator and cytokine production in lipopolysaccharide- (LPS-) stimulated RAW 264.7 macrophages. BHSST markedly inhibited the production of nitric oxide (NO), prostaglandin $\mathrm{E}_{2}\left(\mathrm{PGE}_{2}\right)$, and interleukin- (IL-) 6. BHSST significantly suppressed the protein expression of toll-like receptor 4 (TLR4) and phosphorylated nuclear factor-kappa B (NF- $\kappa$ B) p65 in RAW 264.7 cells. Second, we examined whether BHSST influences the production of chemokines and STAT1 phosphorylation in tumor necrosis factor- $\alpha$ /interferon- $\gamma$ TI-stimulated HaCaT keratinocytes. BHSST significantly suppressed the production of RANTES/CCL5, TARC/CCL17, MDC/CCL22, and IL-8 in TI-stimulated HaCaT cells. BHSST also suppressed TIinduced phosphorylation of STAT1 in HaCaT cells. These results suggest that BHSST may be useful as an anti-inflammatory agent, especially for inflammatory skin diseases.
\end{abstract}

\section{Introduction}

Inflammation is a protective response to pathogens such as bacteria, viruses, and parasites. Coordinate regulation of inflammatory mediator and cytokine release is necessary for optimal host defense. Nitric oxide (NO) and prostaglandin $\mathrm{E}_{2}\left(\mathrm{PGE}_{2}\right)$, important inflammatory mediators, are secreted by activated immune cells, such as macrophages. Under pathological conditions, NO production is increased by inducible NOS (iNOS) and subsequently leads to cytotoxicity and tissue damage. $\mathrm{PGE}_{2}$ is produced at inflammatory sites by cyclooxygenase-2 (COX-2), which is therefore implicated as an important mediator in the processes of inflammation. In addition, tumor necrosis factor- $\alpha$ (TNF- $\alpha$ ) and interleukin(IL-) 6 are proinflammatory cytokines that act as signaling molecules for immune cells and coordinate inflammatory responses.

Toll-like receptors (TLRs) mediate signal transduction cascades that ultimately promote the nuclear translocation of nuclear factor-kappa B (NF- $\kappa$ B). In particular, TLR4 is a pattern recognition receptor for lipopolysaccharide (LPS) [1]. NF- $\kappa \mathrm{B}$ signaling is considered a pivotal mechanism for the regulation of immune and inflammatory responses by controlling the transcription of inflammatory cytokines [2].

However, overproduction of these inflammatory mediators and cytokines can result in various pathological conditions $[3,4]$. In particular, atopic dermatitis- (AD-) like inflammatory skin diseases are aggravated by inflammatory mediators and cytokines in chronic states of inflammation [5]. Migration of inflammatory cells into lesioned skin is 
TABle 1: Composition of Banhasasim-tang.

\begin{tabular}{lccc}
\hline Latin name & Scientific name & Amount (g) & Origin \\
\hline Pinelliae Tuber & Pinellia ternata & 7.500 & China \\
Scutellariae Radix & Scutellaria baicalensis & 5.625 & Gurye, Korea \\
Ginseng Radix & Panax ginseng & 5.625 & Yeongju, Korea \\
Glycyrrhizae Radix et Rhizoma & Glycyrrhiza uralensis & 5.625 & China \\
Zingiberis Rhizoma & Zingiber officinale & 3.750 & Taean, Korea \\
Coptidis Rhizoma & Coptis japonica & 1.875 & China \\
Zingiberis Rhizoma Crudus & Zingiber officinale & 3.750 & Ulsan, Korea \\
Zizyphi Fructus & Ziziphus jujuba & 3.750 & Yeongcheon, Korea \\
\hline Total & & 37.50 & \\
\hline
\end{tabular}

regulated by inflammatory chemokines, a group of small cytokines produced by various cell types. In particular, Th2type cell-specific chemokines, such as regulated on activation, normal T-cell expressed and secreted (RANTES/CCL5), thymus- and activation-regulated chemokine (TARC/CCL17) and macrophage-derived chemokine (MDC/CCL22), are produced from keratinocytes, and may be effective targets for the treatment of inflammatory skin diseases [6]. In addition, IL- 8 is also an important mediator in inflammatory skin diseases [7].

Traditional herbal formulas have been widely used over several thousand years to prevent and treat various diseases in East Asia, including Korea, China, and Japan [8]. Among them, Banhasasim-tang (BHSST, Hange-shashin-to, and Ban xia xie xin tang), comprising eight medicinal herbs (Table 1), has been used for treating gastritis, diarrhea and gastric ulcer $[9,10]$. Despite previous reports, there have been no reported studies on the effects or action mechanisms of BHSST on inflammatory responses.

In this study, we investigated the anti-inflammatory effects of BHSST in RAW 264.7 macrophages and HaCaT keratinocytes in vitro.

\section{Materials and Methods}

2.1. Plant Materials. The eight medicinal herbs forming BHSST were purchased from Kwangmyungdang (Ulsan, Korea). The origin of eight medicinal herbs was confirmed taxonomically by Professor Je-Hyun Lee, Dongguk University, Gyeongju, Republic of Korea. A voucher specimen (2012-KE38-1 KE38-8) has been deposited at the Herbal Medicine Formulation Research Group, Korea Institute of Oriental Medicine.

2.2. Chemicals and Reagents. Liquiritin, coptisine, baicalin, palmatine, berberine, glycyrrhizin, and wogonin were purchased from Wako Chemicals (Osaka, Japan). Wogonoside was purchased from Tauto Biotech (Shanghai, China) and baicalein was purchased from Sigma-Aldrich (St. Louis, MO, USA). The purity of each component was determined $\geq 98 \%$ by HPLC analysis. The chemical structures of the nine marker compounds are shown in Figure 1. HPLC-grade reagents, methanol, acetonitrile, and water were obtained from J.T. Baker (Phillipsburg, NJ, USA). Trifluoroacetic acid, lipopolysaccharide (LPS) from Escherichia coli, $N^{G}$-methyl-L-arginine (L-NMMA), indomethacin, and Cellytic MT Cell Lysis Reagent were purchased from SigmaAldrich. Dulbecco's modified Eagle's medium (DMEM), fetal bovine serum (FBS), penicillin-streptomycin, and phosphate-buffered saline (PBS) were obtained from Gibco BRL (Grand Island, CA, USA). The Cell Counting Kit-8 (CCK-8) used was a product of Dojindo (Kumamoto, Japan). Griess reagent and $\mathrm{PGE}_{2}$ enzyme-linked immunosorbent assay (ELISA) kit were purchased from Promega Corporation (Madison, WI, USA) and Cayman Chemical Co. (Ann Arbor, MI, USA), respectively. Mouse TNF- $\alpha$ and IL-6 ELISA kits and Trizol reagent were obtained from Invitrogen (Camarillo, CA, USA). Human recombinant TNF- $\alpha$ and interferon- $\gamma$ (IFN- $\gamma$ ), and human chemokine (RANTES, TARC, MDC, and IL-8) ELISA kits were purchased from R\&D Systems Inc. (Minneapolis, MN, USA). An iScript cDNA Synthesis kit and Protein Assay Dye Reagent Concentrate were purchased from Bio-Rad Laboratories (Hercules, CA, USA). The enhanced chemiluminescence (ECL) kit used was a product of Thermo Fisher Scientific (Waltham, MA, USA).

2.3. Preparation of BHSST Decoction. BHSST comprised eight herbs (Table 1 , total weight $=5.0 \mathrm{~kg}$, about 133.3 times the composition of a single dose) and was extracted in distilled water at $100^{\circ} \mathrm{C}$ for $2 \mathrm{~h}$ under pressure $(98 \mathrm{kPa})$ using an electric extractor (COSMOS-660; Kyungseo Machine Co., Incheon, Korea). The extract solution was filtered using a standard sieve (No. 270, $53 \mu \mathrm{m}$ ) and freeze-dried. The yield of extract was $14.99 \%$ (749.5 g). For quantitative analysis, lyophilized BHSST extract (200 mg) was dissolved in $70 \%$ methanol $(20 \mathrm{~mL})$ and mixed. Subsequently, the solution was diluted 10 -fold with $70 \%$ methanol for quantitative analysis of baicalin and wogonoside. The solution was filtered through a SmartPor GHP syring filter $(0.2 \mu \mathrm{m}$ pore size, Woongki Science, Seoul, Korea) before injection into the HPLC system.

2.4. Quantitative Analysis of the Marker Constituents in BHSST. The quantitative determination was performed with a Shimadzu Prominence LC-20A series HPLC system (Kyoto, Japan) consisting of a solvent delivery unit (LC-20AT), online degasser (DGU-20A 3 ), column oven (CTO-20A), auto sample injector (SIL-20AC), and photodiode array detector (SPD-M20A). Data were collected and processed using LCsolution software (version 1.24; Shimadzu, Kyoto, Japan). 
<smiles>O=C1C[C@H](c2ccc(OC(O)C(O)C(O)CO)cc2)Oc2cc(O)ccc21</smiles>

Liquiritin<smiles>COc1cc2c(cc1OC)-c1cc3ccc(OC)c(OC)c3c[n+]1CC2</smiles>

Palmatine

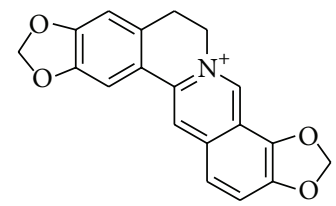

Coptisine<smiles>COc1ccc2cc3[n+](cc2c1OC)CCc1cc2c(cc1-3)OCO2</smiles>

Berberine<smiles>O=C(O)C1C(O)OC(Oc2cc3oc(-c4ccccc4)cc(=O)c3c(O)c2O)C(O)C1O</smiles>

Baicalin<smiles>COc1c(OC2OC(C(=O)O)C(O)C(O)C(O)C2O)cc(O)c2c(=O)cc(-c3ccccc3)oc12</smiles>

Wogonoside<smiles>COc1c(O)cc(O)c2c(=O)cc(-c3ccccc3)oc12</smiles>

Wogonin

FIGURE 1: Chemical structures of the nine marker compounds in Banhasasim-tang.

The marker compounds were separated on a Gemini $\mathrm{C}_{18}$ column $(250 \mathrm{~mm} \times 4.6 \mathrm{~mm}$; particle size $5 \mu \mathrm{m}$; Phenomenex, Torrance, CA, USA) maintained at $40^{\circ} \mathrm{C}$. The mobile phases consisted of $0.1 \%(\mathrm{v} / \mathrm{v})$ trifluoroacetic acid in distilled water (A) and acetonitrile (B). The gradient flow was as follows: $10-60 \%$ B for $0-30 \mathrm{~min}, 60-100 \%$ B for $30-40 \mathrm{~min}, 100 \% \mathrm{~B}$ for $40-45 \mathrm{~min}$, and $100-10 \% \mathrm{~B}$ for $45-50 \mathrm{~min}$. The analysis was conducted at a flow-rate of $1.0 \mathrm{~mL} / \mathrm{min}$ with PDA detection at $254 \mathrm{~nm}$ (glycyrrhizin), $275 \mathrm{~nm}$ (liquiritin, baicalin, wogonoside, baicalein, and wogonin), and $350 \mathrm{~nm}$ (coptisine, palmatine, and berberine). The injection volume was $10 \mu \mathrm{L}$.

2.5. Cell Culture. The murine macrophage RAW 264.7 cells and human keratinocyte $\mathrm{HaCaT}$ cells were obtained from the American Type Culture Collection (Rockville, MD, USA) and CLS Cell Lines Service (Eppelheim, Baden-Württemberg, Germany), respectively. RAW 264.7 cells were cultured in DMEM, which was supplemented with $5.5 \%$ heat-inactivated FBS, penicillin $(100 \mathrm{U} / \mathrm{mL})$ and streptomycin $(100 \mu \mathrm{g} / \mathrm{mL})$ in a $5 \% \mathrm{CO}_{2}$ incubator at $37^{\circ} \mathrm{C}$. HaCaT cells were cultured in DMEM supplemented with $10 \%$ heat-inactivated FBS, penicillin $(100 \mathrm{U} / \mathrm{mL})$, and streptomycin $(100 \mu \mathrm{g} / \mathrm{mL})$ in a $5 \%$ $\mathrm{CO}_{2}$ incubator at $37^{\circ} \mathrm{C}$.

2.6. Cytotoxicity Assay. Cell viability was assessed using a CCK-8 kit according to the manufacturer's instructions. RAW 264.7 cells $\left(3 \times 10^{3}\right.$ cells/well $)$ and HaCaT cells $(1 \times$ $10^{3}$ cells/well) were incubated in 96-well plates with various concentrations of BHSST in the absence or presence of respective LPS $(1 \mu \mathrm{g} / \mathrm{mL})$ and TNF- $\alpha$ and IFN- $\gamma$
(TI, each $10 \mathrm{ng} / \mathrm{mL}$ ) for $24 \mathrm{~h}$. The CCK-8 reagent was added to each well, followed by incubation for an additional $4 \mathrm{~h}$. Absorbance by well contents was measured at $450 \mathrm{~nm}$ using a Benchmark plus microplate reader (Bio-Rad Laboratories). The percentage of viable cells was calculated using the following formula: cell viability $(\%)=($ mean absorbance in test wells/mean absorbance in control wells) $\times 100$.

2.7. Measurement of Inflammatory Mediator Levels. RAW 264.7 cells $\left(2.5 \times 10^{5}\right.$ cells/well $)$ were cultured in 48 -well plates. After reaching confluence, the cells were treated with various concentrations of BHSST for $4 \mathrm{~h}$, and then stimulated with $1 \mu \mathrm{g} / \mathrm{mL}$ of LPS for $20 \mathrm{~h}$. The culture supernatants were used to determine levels of secreted nitrite, $\mathrm{PGE}_{2}, \mathrm{TNF}-\alpha$ and IL-6. The nitrite production was measured by Griess reagent as an indicator of $\mathrm{NO}$, and the $\mathrm{PGE}_{2}, \mathrm{TNF}-\alpha$, and IL6 production were determined using ELISA kits. L-NMMA and indomethacin were used as positive controls for $\mathrm{NO}$ and $\mathrm{PGE}_{2}$, respectively.

2.8. Measurement of Chemokine Production. HaCaT cells $(1 \times$ $10^{6}$ cells/well) were cultured in 6-well plates. After reaching confluence, the cells were washed and treated with various concentrations of BHSST in $1 \mathrm{~mL}$ of serum-free medium that contained TI (each $10 \mathrm{ng} / \mathrm{mL}$ ) for $24 \mathrm{~h}$. The supernatants were harvested, and production of RANTES, TARC, MDC, and IL8 were determined using ELISA kits.

2.9. Western Blotting. To determine the effect of BHSST on expression of COX-2, TLR 4 , and phosphorylated NF- $\kappa \mathrm{B}$ in RAW 264.7 cells, the cells were pretreated with various 


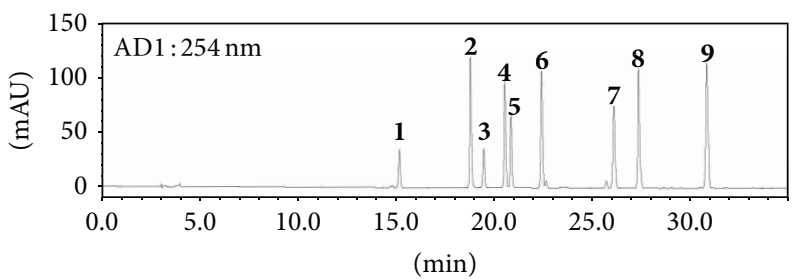

(a)

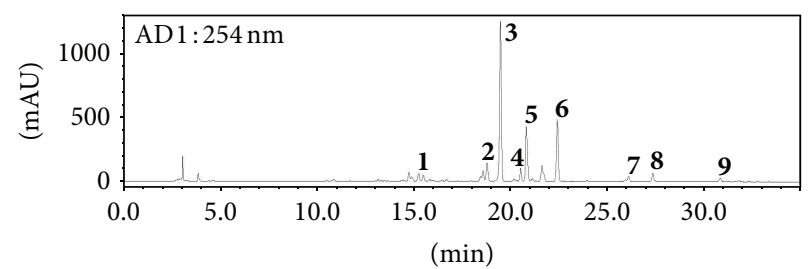

(b)

FiguRE 2: HPLC chromatograms of the standard mixture (a) and Banhasasim-tang extract (b) at $254 \mathrm{~nm}$. Liquiritin (1), coptisine (2), baicalin (3), palmatine (4), berberine (5), wogonoside (6), baicalein (7), glycyrrhizin (8), and wogonin (9).

TABLE 2: Contents of the nine marker components in the Banhasasim-tang by HPLC $(n=3)$.

\begin{tabular}{lcccc}
\hline Compound & Mean $(\mathrm{mg} / \mathrm{g})$ & SD & RSD (\%) & Source \\
\hline Liquiritin & 5.412 & 0.014 & 0.253 & G. uralensis \\
Coptisine & 2.222 & 0.009 & 0.424 & C. japonica \\
Baicalin & 48.340 & 0.253 & 0.524 & S. baicalensis \\
Palmatine & 1.649 & 0.006 & 0.363 & C. japonica \\
Berberine & 3.909 & 0.001 & 0.038 & C. japonica \\
Wogonoside & 15.858 & 0.032 & 0.204 & S. baicalensis \\
Baicalein & 0.977 & 0.008 & 0.782 & S. baicalensis \\
Glycyrrhizin & 5.347 & 0.016 & 0.300 & G. uralensis \\
Wogonin & 1.087 & 0.002 & 0.145 & S. baicalensis \\
\hline
\end{tabular}

concentrations of BHSST for $2 \mathrm{~h}$, and then stimulated with LPS $(1 \mu \mathrm{g} / \mathrm{mL})$ for $14 \mathrm{~h}$ and $30 \mathrm{~min}$, respectively. HaCaT cells were treated with $\mathrm{TI}$ in the presence or absence of various concentrations of BHSST for $30 \mathrm{~min}$ to investigate the influence of BHSST on STAT1 activation. The cells were collected by centrifugation and washed twice with PBS. Proteins of whole cells were extracted using CelLytic MT Cell Lysis Reagent containing protease inhibitors. Nuclear proteins were extracted using NE-PER Nuclear and Cytoplasmic Extraction Reagents (Thermo Fisher Scientific Inc., Waltham, MA, USA) according to the manufacturer's protocol. The protein concentration was determined using a Protein Assay Dye Reagent Concentrate according to the manufacturer's instructions. Total proteins $(15-20 \mu \mathrm{g})$ were resolved by $10 \%$ sodium dodecyl sulfate-polyacrylamide gel electrophoresis (SDS-PAGE) and transferred to PVDF membranes. The membranes were immediately blocked with 5\% skim milk in Tris-buffered saline containing $0.1 \%$ Tween-20 ( $\mathrm{pH} 7.4$ ) (TBST), followed by incubation with primary antibodies against COX-2 (Santa Cruz Biotechnology, Santa Cruz, CA, USA), TLR4 (Santa Cruz Biotechnology), phospho-NF- $\kappa$ B p65 (Cell Signaling Tech., Danvers, MA, USA), STAT-1 (Abcam, Cambridge, MA, USA), phospho-STAT1 (Abcam), and $\beta$-actin (Cell Signaling Tech., Danvers, MA, USA) at $4^{\circ} \mathrm{C}$ overnight. After washing three times with TBST, the membranes were incubated with a horseradish peroxidase- (HRP-) conjugated secondary antibody (Jackson Immuno Research, PA, USA) for $1 \mathrm{~h}$ at room temperature. The membranes were washed three times with TBST, and then developed using an ECL kit. The membranes were photographed using a ChemiDoc $\mathrm{XRS}^{+}$imaging system (Bio-Rad Laboratories).
2.10. Immunofluorescence Staining. Cells were seeded onto glass coverslips and incubated with TI (each $10 \mathrm{ng} / \mathrm{mL}$ ) in the absence or presence of BHSST $(500 \mu \mathrm{g} / \mathrm{mL})$ for $30 \mathrm{~min}$. The cells were fixed in $4 \%$ paraformaldehyde and $100 \%$ acetone, blocked in $0.5 \%$ bovine serum albumin, and incubated with anti-STAT1 antibody (Cell Signaling Tech.) for $1 \mathrm{~h}$ at room temperature. Then, FITC-conjugated anti-rabbit immunoglobulin G (IgG) antibody (Invitrogen, Carlsbad, CA, USA) was used as a secondary antibody. The immunostained cells were mounted with medium containing DAPI and visualized by use of an Olympus FLUOVIEW FV10i confocal microscope (Tokyo, Japan).

2.11. Statistics. All data are presented as the mean \pm SEM. One-way analysis of variance was used to detect significant differences between the control and treatment groups. Dunnett's test was used for multiple comparisons. The differences were considered significant at $P<0.05$ and $P<0.01$.

\section{Results}

3.1. Quantitative Determination of the Nine Compounds in BHSST. The established HPLC analytical method was applied for the simultaneous quantification of nine compounds in BHSST. The typical chromatogram patterns for standard compounds and the BHSST decoction are shown in Figure 2. The retention times of the liquiritin, coptisine, baicalin, palmatine, berberine, wogonoside, baicalein, glycyrrhizin, and wogonin were detected at approximately 15.14 , $18.80,19.45,20.54,20.84,22.41,26.10,27.36$, and $30.85 \mathrm{~min}$, respectively. The concentrations of the nine components were $0.977-48.340 \mathrm{mg} / \mathrm{g}$ and the results are summarized in Table 2. 


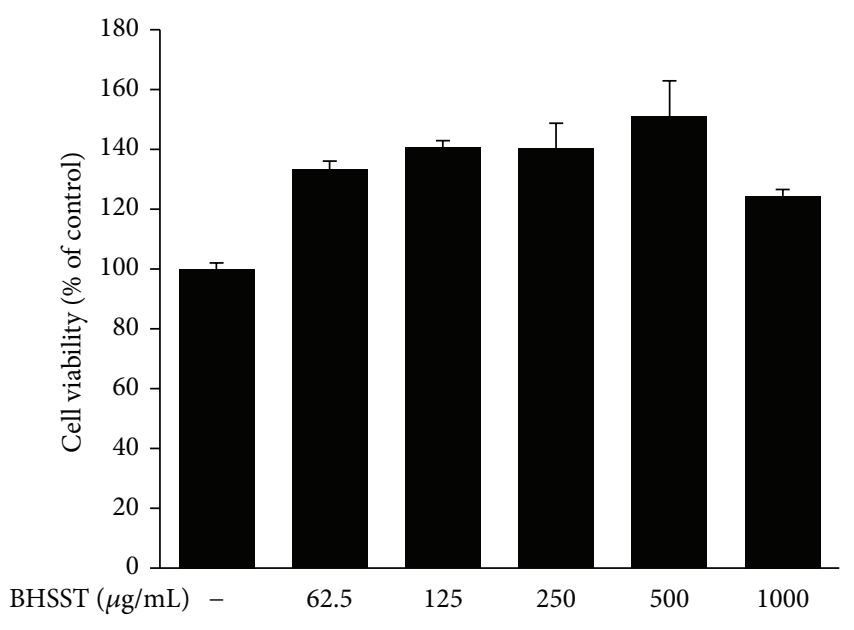

(a)

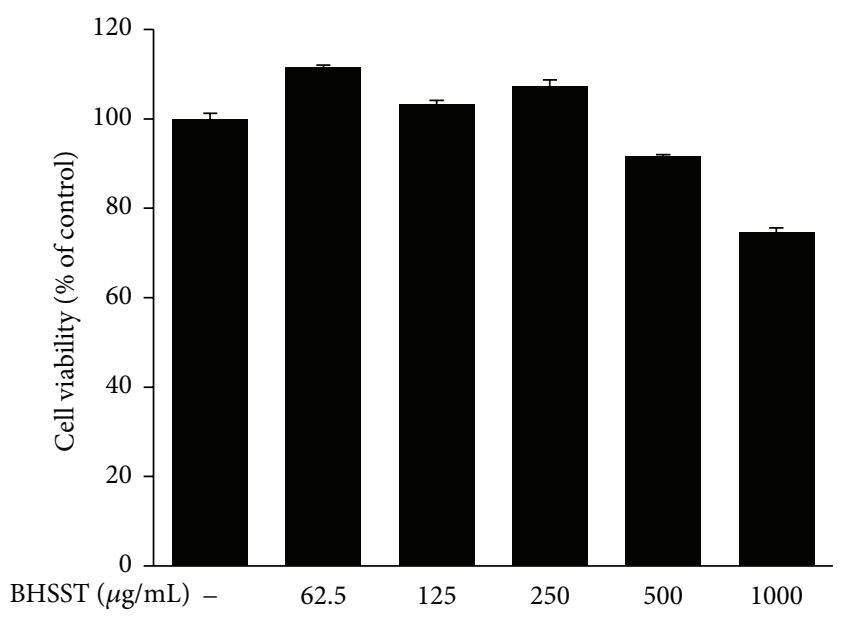

(c)

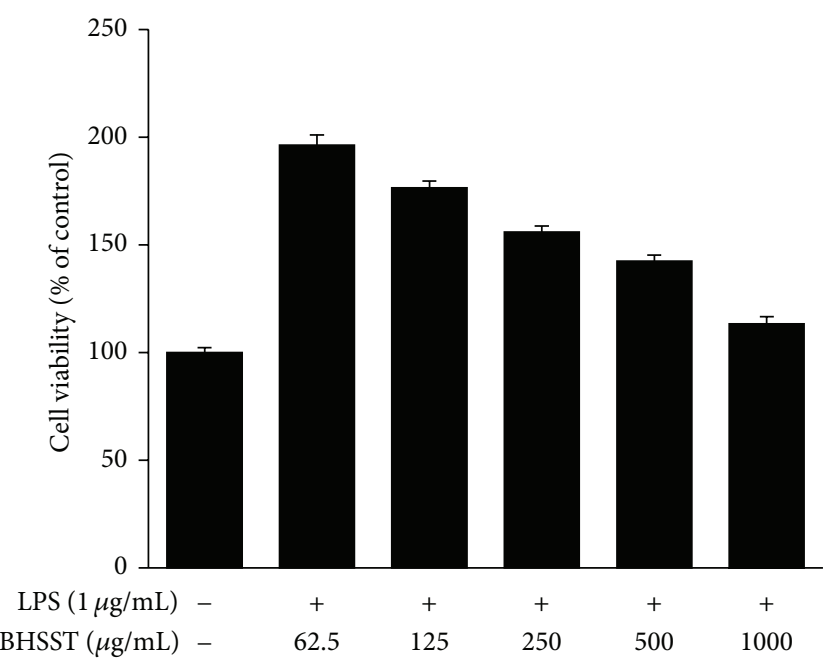

(b)

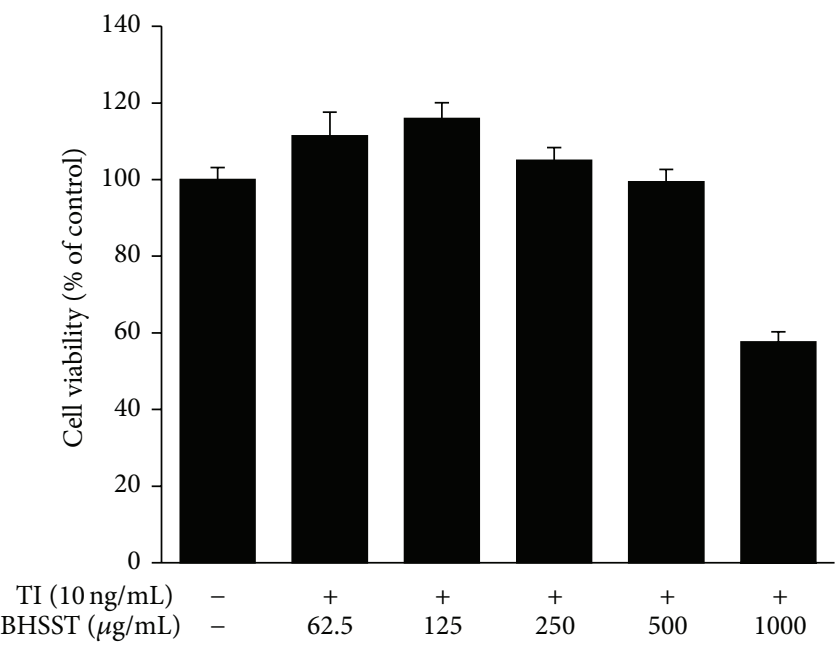

(d)

FIGURE 3: Cytotoxic effects of Banhasasim-tang (BHSST) in RAW 264.7 cells and HaCaT cells. RAW 264.7 cells (a) and HaCaT cells (c) were seeded in to 96-well plates and treated with various concentrations of BHSST for $24 \mathrm{~h}$. (b) RAW 264.7 cells were cotreated with various concentrations of BHSST, and LPS $(1 \mu \mathrm{g} / \mathrm{mL})$ for $24 \mathrm{~h}$. (d) HaCaT cells were cotreated with various concentrations of BHSST, and TNF- $\alpha$ and IFN- $\gamma$ (each $10 \mathrm{ng} / \mathrm{mL}$, TI) for $24 \mathrm{~h}$. Cell viability was assessed using a CCK-8 kit. The values are expressed as mean \pm SEM of three independent experiments.

3.2. Effects of BHSST on Inflammatory Mediators in RAW 264.7 Cells. The cytotoxicity of BHSST in the absence or presence of LPS $(1 \mu \mathrm{g} / \mathrm{mL})$ for $24 \mathrm{~h}$ was determined in RAW 264.7 cells (Figures 3(a) and 3(b)), and subsequent experiments were performed at nontoxic concentrations. To investigate the anti-inflammatory effect of BHSST, we measured NO, $\mathrm{PGE}_{2}$, and IL-6 levels in LPS-stimulated RAW 264.7 cells. As shown in Figure 4, LPS-treated RAW 264.7 cells significantly increased NO, PGE 2 , TNF- $\alpha$ and IL- 6 levels compared with the vehicle-treated cells $(P<0.01)$. By contrast, BHSST $(250$, 500 or $1000 \mu \mathrm{g} / \mathrm{mL}$ ) suppressed LPS-induced NO, $\mathrm{PGE}_{2}$, and IL-6 production in a dose-dependent manner compared with cells treated with LPS alone $(P<0.01)$ (Figure 4$)$. However, BHSST had no effect on LPS-induced TNF- $\alpha$ production in RAW 264.7 cells (data not shown). Positive controls using
L-NMMA and indomethacin showed significant decreases in LPS-stimulated $\mathrm{NO}$ and $\mathrm{PGE}_{2}$ production, respectively (Figures 4(a) and 4(b)).

3.3. Effects of BHSST on Expression of COX-2, TLR4, and Phosphorylated NF- $\kappa$ B in RAW 264.7 Cells. As shown in Figure 5, LPS markedly induced expression of COX-2 and TLR4 compared with the vehicle in RAW 264.7 cells. BHSST had no significantly inhibition on LPS-stimulated COX-2 expression (Figures 5(a) and 5(b)). By contrast, BHSST reduced LPSstimulated TLR4 expression at a dose of $1000 \mu \mathrm{g} / \mathrm{mL}(P<$ 0.01) (Figures 5(a) and 5(c)). To determine whether BHSST mediates the inhibition of inflammatory responses through NF- $\kappa$ B pathway, phosphorylation of NF- $\kappa$ B p 65 was analyzed by Western blotting. As shown in Figure 6, phosphorylation 


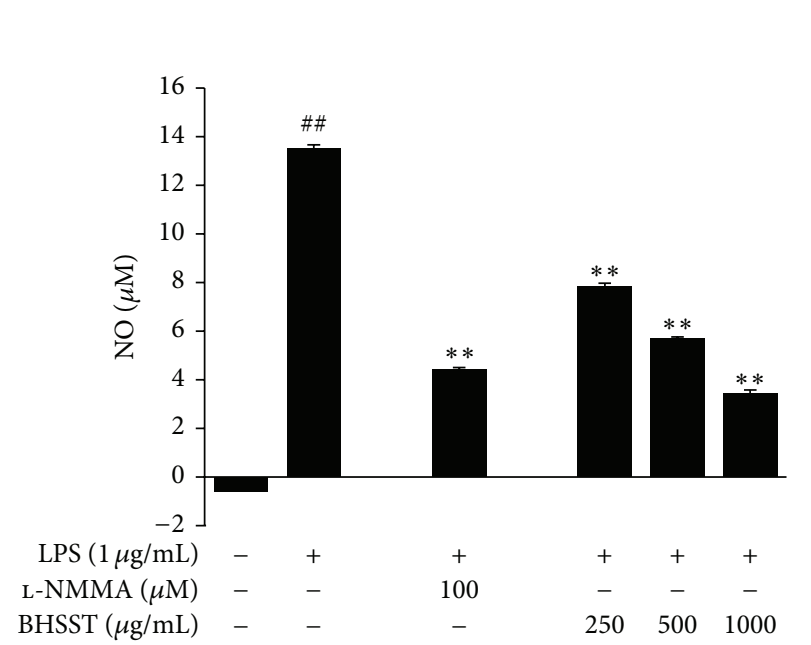

(a)

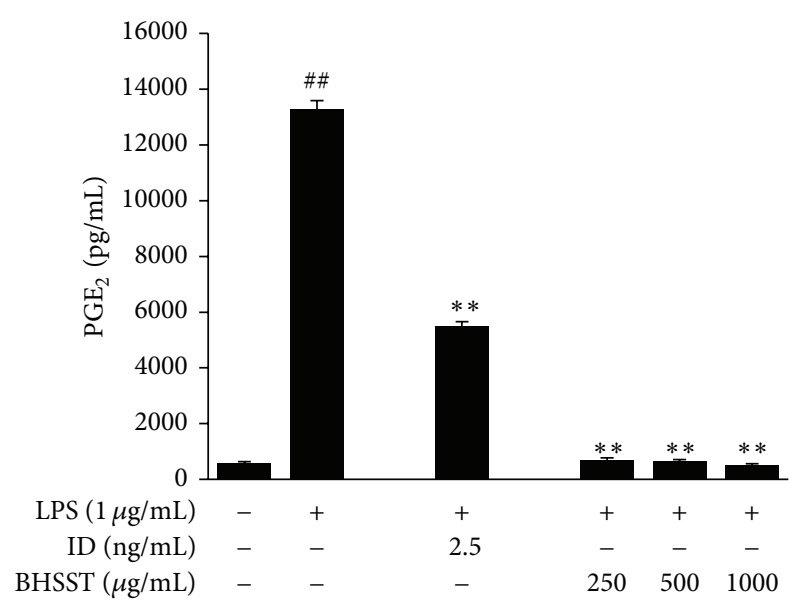

(b)

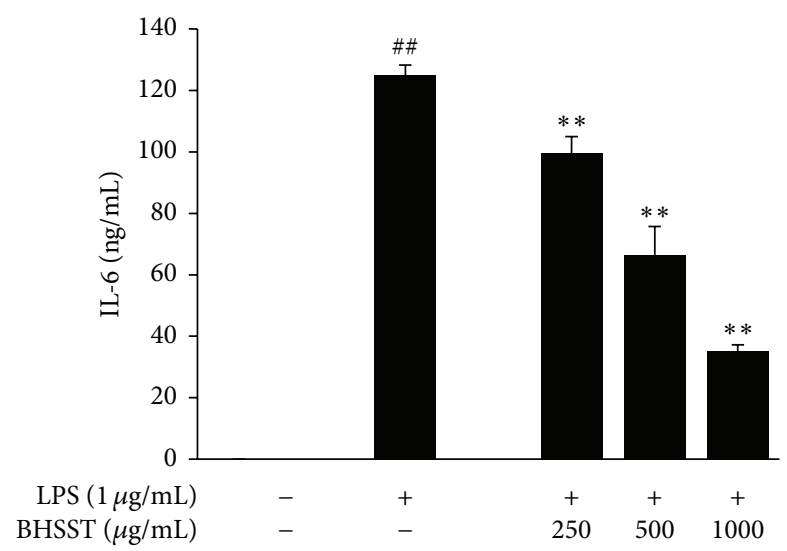

(c)

FIGURE 4: Effects of Banhasasim-tang (BHSST) on production of inflammatory mediators and cytokine in RAW 264.7 cells. Cells were pretreated with BHSST $(250,500$ or $1000 \mu \mathrm{g} / \mathrm{mL})$ for $4 \mathrm{~h}$ and then stimulated with LPS $(1 \mu \mathrm{g} / \mathrm{mL})$ for $20 \mathrm{~h}$. NO production was measured

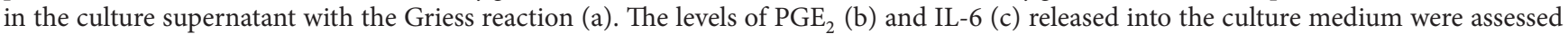
using commercially available ELISA kits. L-NMMA and indomethacin (ID) were used as positive controls for NO and PGE 2 , respectively. Values are expressed as mean \pm SEM of three independent experiments. Each bar represents the mean of three independent experiments. ${ }^{\# \#} P<0.01$ versus vehicle control cells; and ${ }^{* *} P<0.01$ versus LPS-treated cells.

of NF- $\kappa$ B p 65 was increased by LPS stimulation. By contrast, BHSST significantly suppressed LPS-stimulated phosphorylation of NF- $\kappa \mathrm{B}$ p 65 at a dose of $1000 \mu \mathrm{g} / \mathrm{mL}(P<0.01)$.

\subsection{Effects of BHSST on Chemokine Production in HaCaT} Cells. The cytotoxicity of BHSST in the absence or presence of TI (each $10 \mathrm{ng} / \mathrm{mL}$ ) for $24 \mathrm{~h}$ was determined in $\mathrm{HaCaT}$ cells (Figures 3(c) and 3(d)), and subsequent experiments were performed at nontoxic concentrations. To investigate the inhibitory effect of BHSST on TI-induced production of RANTES, TARC, MDC, and IL-8, HaCaT cells were cotreated with BHSST $(125,250$, or $500 \mu \mathrm{g} / \mathrm{mL})$ and TI for $24 \mathrm{~h}$. The production of RANTES, TARC, MDC, and IL- 8 was measured by ELISA. The TI stimulation significantly increased production of RANTES, TARC, MDC, and IL-8 compared with the vehicle in HaCaT cells (Figures 7(a)-7(d)). By contrast, BHSST suppressed TI-stimulated RANTES and TARC production at a dose of $500 \mu \mathrm{g} / \mathrm{mL}$ $(P<0.01)$ (Figures $7(\mathrm{a})$ and $7(\mathrm{~b}))$. The increased MDC and IL- 8 production brought about by TI stimulation were significantly decreased by BHSST in a dose-dependent manner (Figures 7(c) and 7(d)). A positive control, silymarin showed a significant decrease in TI-stimulated chemokine production.

3.5. Effects of BHSST on STAT1 Phosphorylation. Previous studies have reported that STAT1 is an important regulator of TI-induced inflammatory and immune responses [11, 12]. Therefore, we examined the effect of BHSST on the phosphorylation of STAT1 in TI-treated HaCaT cells. As shown in Figure 8, phosphorylation of STAT1 was increased by TI treatment. BHSST clearly inhibited TI-induced phosphorylation 


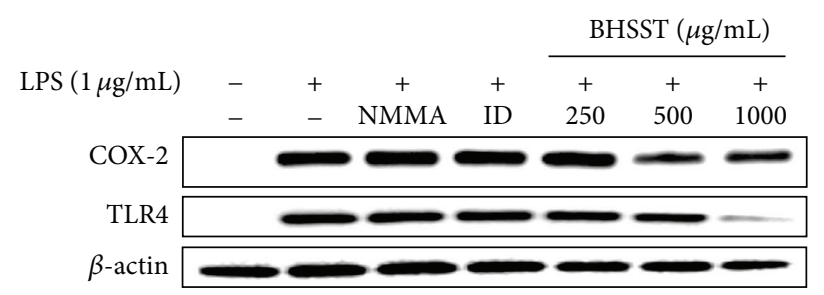

(a)

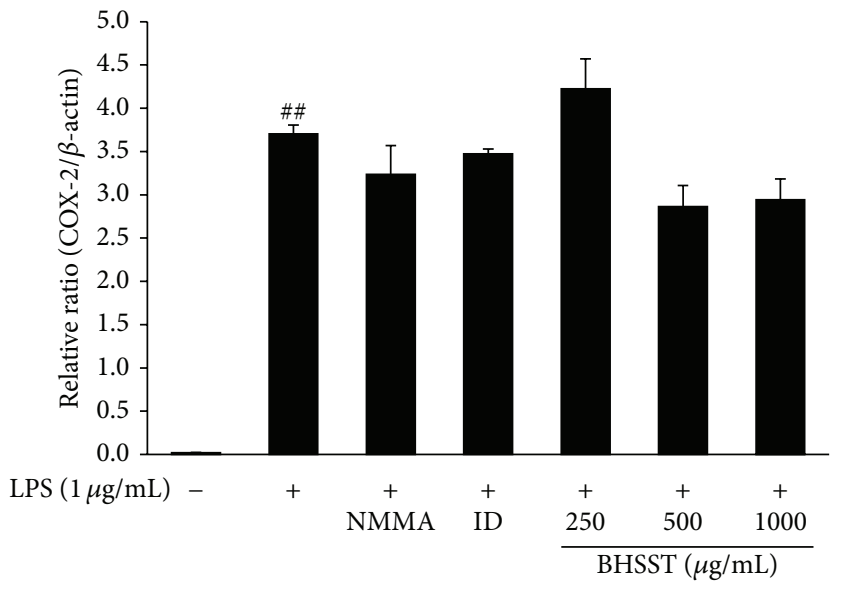

(b)

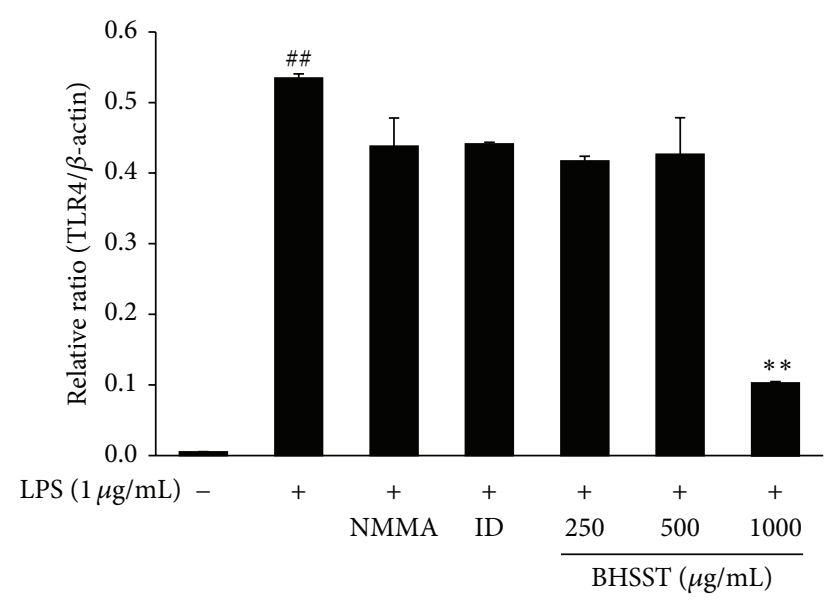

(c)

FIGURE 5: Effects of Banhasasim-tang (BHSST) on COX-2 and TLR4 expression in RAW 264.7 cells. Cells were pretreated with BHSST $(250,500$ or $1000 \mu \mathrm{g} / \mathrm{mL})$ for $2 \mathrm{~h}$ and then stimulated with LPS $(1 \mu \mathrm{g} / \mathrm{mL})$ for $14 \mathrm{~h}$. (a) Protein expression of COX-2 and TLR4 was analyzed by Western blotting. The relative abundance of protein was calculated as COX-2/ $\beta$-actin ratio (b) and TLR $4 / \beta$-actin ratio (c). Values are expressed as mean \pm SEM of three independent experiments. ${ }^{\#} P<0.01$ versus vehicle control cells; and ${ }^{* *} P<0.01$ versus LPS-treated cells.

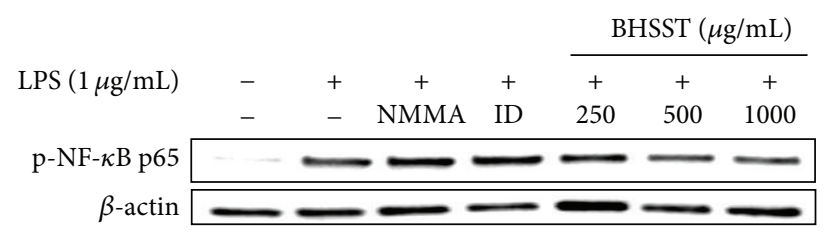

(a)

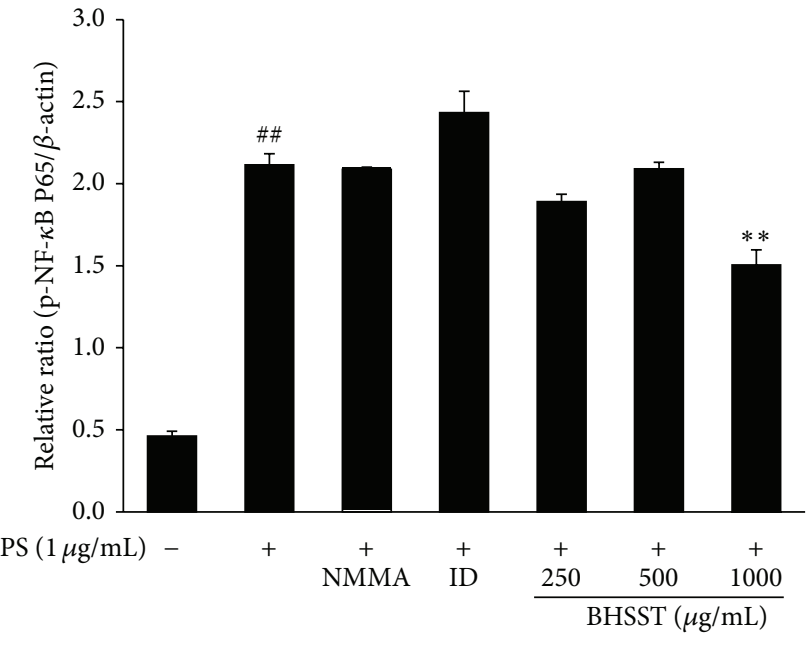

(b)

FIGURE 6: Effect of Banhasasim-tang (BHSST) on NF- $\kappa$ B activation in RAW 264.7 cells. Cells were pretreated with BHSST (250, 500 or $1000 \mu \mathrm{g} / \mathrm{mL}$ ) for $2 \mathrm{~h}$ and then stimulated with LPS $(1 \mu \mathrm{g} / \mathrm{mL}$ ) for $30 \mathrm{~min}$. (a) Protein expression of phospho-NF- $\kappa \mathrm{B}$ p65 was analyzed by Western blotting. The relative abundance of protein was calculated as phospho-NF- $\kappa \mathrm{B}$ p $65 / \beta$-actin ratio. Values are expressed as mean \pm SEM of three independent experiments. ${ }^{\# \#} P<0.01$ versus vehicle control cells; and ${ }^{* *} P<0.01$ versus LPS-treated cells. 


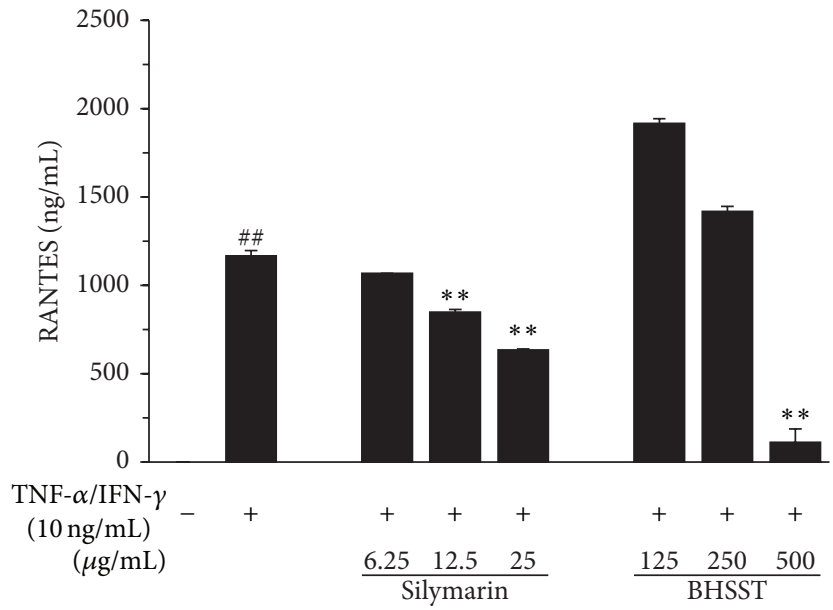

(a)

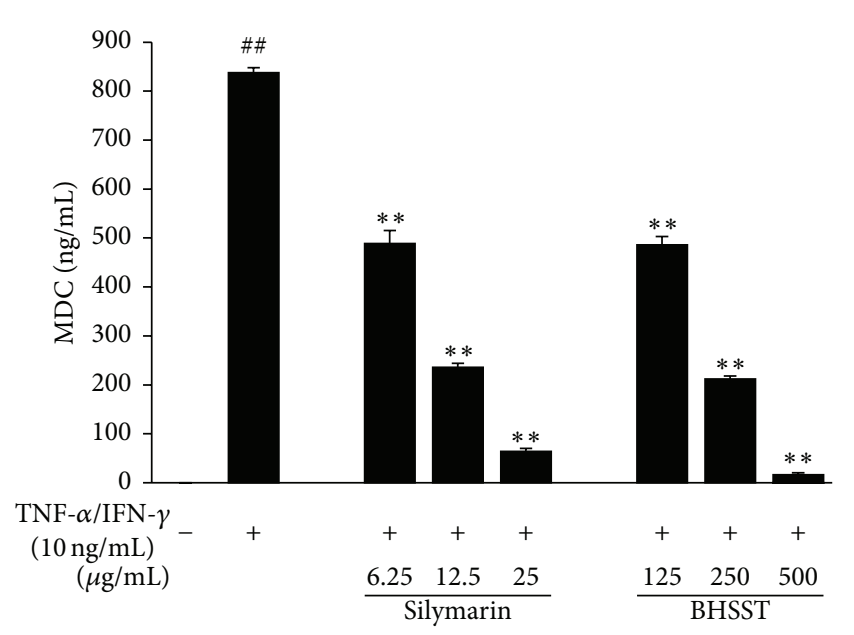

(c)

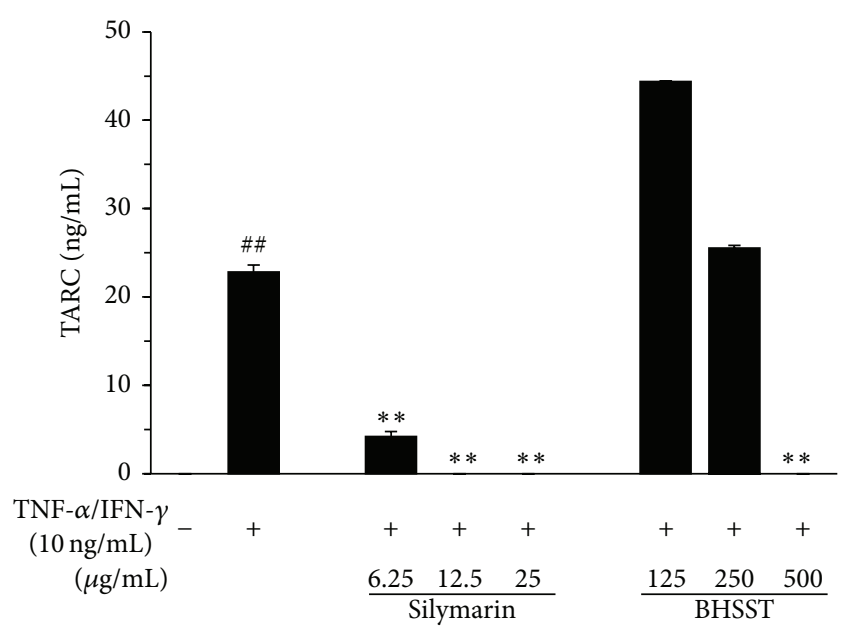

(b)

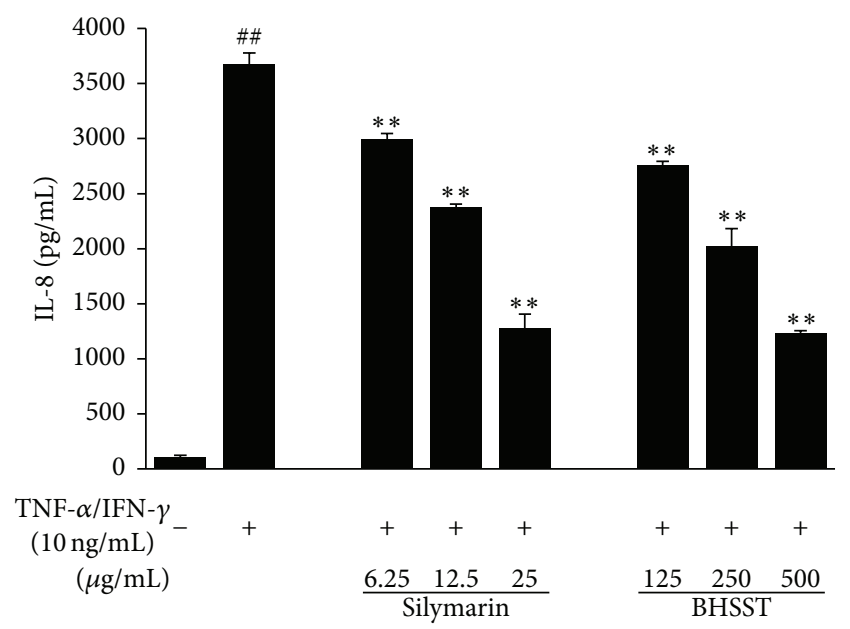

(d)

FIGURE 7: Effects of Banhasasim-tang (BHSST) on production of chemokines in HaCaT cells. Production of RANTES (a), TARC (b), MDC (c), and IL-8 (d) were measured using the culture supernatant. Cells were cotreated with BHSST (125, 250, or 500 $\mu \mathrm{g} / \mathrm{mL})$, and TNF- $\alpha$ and IFN- $\gamma$ (TI, each $10 \mathrm{ng} / \mathrm{mL})$ for $24 \mathrm{~h}$. Silymarin $(6.25,12.5$, or $25 \mu \mathrm{g} / \mathrm{mL})$ was used as a positive control. Values are expressed as mean \pm SEM of three independent experiments. ${ }^{\# \#} P<0.01$ versus vehicle control cells; and ${ }^{* *} P<0.01$ versus TI-treated cells.

of STAT1. Treatment of silymarin reduced STAT1 phosphorylation (Figure 8(a)). Consistently, immunofluorescent staining revealed that BHSST blocked TI-induced nuclear localization of STAT1 in HaCaT cells (Figure 8(b)).

\section{Discussion}

BHSST, a traditional Korean herbal formula, has been used for the treatment of acute or chronic gastritis, diarrhea, and gastric ulcer $[9,10]$. BHSST consists of eight medicinal herbs, Pinelliae Tuber, Scutellariae Radix, Ginseng Radix, Glycyrrhizae Radix et Rhizoma, Zingiberis Rhizoma, Coptidis Rhizoma, Zingiberis Rhizoma Crudus, and Zizyphi Fructus in $4: 3: 3: 3: 2: 1: 2: 2$ proportions. The main constituents of each herbal medicine are known as follows: phenolic acid (e.g., homogentisic acid) and phenolic aldehyde (e.g., 3,4-dihydroxybenzaldehyde) from Pinelliae Tuber [13], flavonoids (e.g., baicalin, wogonoside, baicalein, and wogonin) from Scutellariae Radix [14], triterpene saponins (e.g., ginsenoside Rb1) from Ginseng Radix [15], triterpene saponin (e.g., glycyrrhizin) and flavonoids (e.g., liquiritin and liquiritigenin) from Glycyrrhizae Radix et Rhizoma [16], phenols (e.g., 6-, 8-, and 10-gingerol) from Zingiberis Rhizoma and Zingiberis Rhizoma Crudus [17], alkaloids (e.g., berberine, coptisine, and palmatine) from Coptidis Rhizoma [18], and flavonoids (e.g., spinosin and 6 "' feruloylspinosin) from Zizyphi Fructus [19].

Among those components, we analyzed nine compounds including baicalin, wogonoside, baicalein, and wogonin (Scutellariae Radix), glycyrrhizin and liquiritin (Glycyrrhizae et Rhizoma), and berberine, coptisine, and palmatine (Coptidis Rhizoma) using HPLC-PDA. An established 


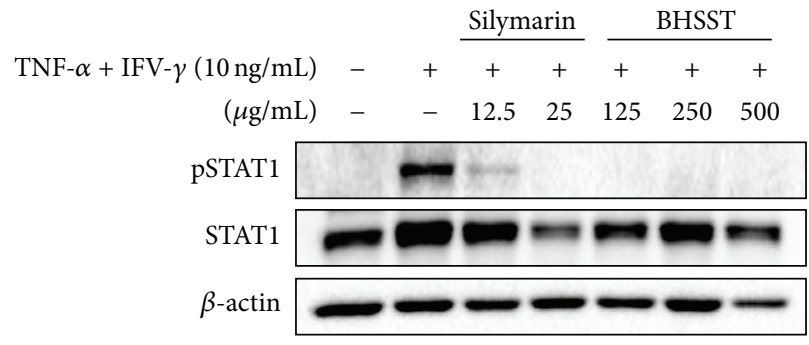

(a)
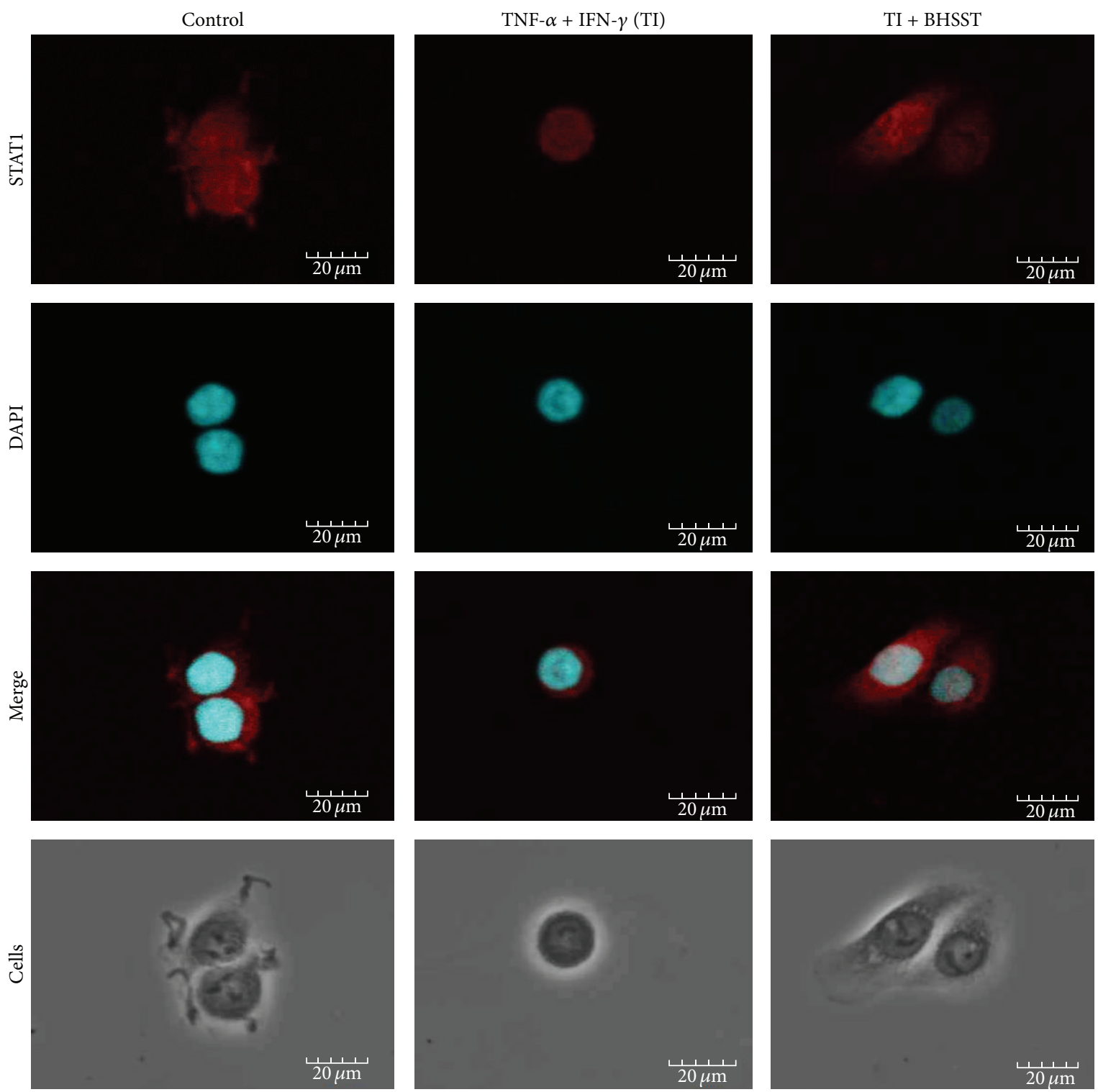

(b)

FIGURE 8: Effect of Banhasasim-tang (BHSST) on TNF- $\alpha$ and IFN- $\gamma$-induced STAT1 activation in HaCaT cells. (a) Expression of total and phosphorylated STAT1 was determined by Western blotting. Cells were cotreated with BHSST (125, 250, or 500 $\mu \mathrm{g} / \mathrm{mL})$, and TNF- $\alpha$ and IFN- $\gamma$ (TI, each $10 \mathrm{ng} / \mathrm{mL}$ ) for $30 \mathrm{~min}$. Silymarin $(12.5 \mathrm{or} 25 \mu \mathrm{g} / \mathrm{mL})$ was used as a positive control. Results are representative of at least three independent experiments. (b) Cellular localization of STAT1 was examined by immunofluorescence staining. Cells were cotreated with BHSST $(500 \mu \mathrm{g} / \mathrm{mL})$, and TI for $30 \mathrm{~min}$. The cells were fixed with $4 \%$ (v/v) methanol-free formaldehyde solution (pH 7.4), stained with anti-STAT1 (red). The stained cells were mounted with medium containing DAPI (blue) and visualized under an Olympus FLUOVIEW FV 10i confocal microscope. 
HPLC-PDA method was applied for simultaneous analysis of the nine compounds in the BHSST sample. Baicalin $(48.340 \mathrm{mg} / \mathrm{g})$, a marker compound of Scutellariae Radix, was detected as the main component alongside other in the sample.

Previous studies demonstrated that Pinellia ternate [20], Scutellaria baicalensis [21], Panax ginseng [22], Glycyrrhiza uralensis [23], Zingiber officinale [24], Coptis japonica [25], and Ziziphus jujuba $[26,27]$ exert the anti-inflammatory and anti-AD effects. In addition, baicalin [28], wogonoside [29], baicalein [30], wogonin [31], and glycyrrhizae [32] have also been reported to exhibit anti-inflammatory and anti-AD effects. In particular, baicalin, the most abundant component in BHSST has been reported that the inhibitory effect on inflammatory mediators, cytokines, and TLR4/NF- $\kappa \mathrm{B}$ pathway activation [33]. Based on previous studies, we predicted that BHSST, containing these bioactive herbs as constituents, would exert beneficial effects on skin inflammatory diseases such as AD. Therefore, we investigated the antiinflammatory effect of BHSST using LPS-stimulated RAW 264.7 macrophages and TI-stimulated HaCaT keratinocytes in vitro.

Inflammatory responses play a central role in the pathogenesis of many diseases, initiated by the invasion of pathogens or by tissue injury, followed by a series of vascular and cellular reactions. Macrophages are principal immune cells, which are activated by inflammatory mediators including $\mathrm{NO}$ and $\mathrm{PGE}_{2}$, as well as inflammatory cytokines such as TNF- $\alpha$, IL- 6 , and IL- $1 \beta$ in inflammatory responses. High levels of these inflammatory mediators and cytokines in states of chronic inflammation can result in various pathological conditions $[3,4]$. Therefore, these inflammatory mediators and cytokines are important targets for treating inflammatory diseases. In the present study, we observed that LPS stimulated the production of NO, PGE 2 , TNF- $\alpha$, and IL- 6 as well as expression of COX-2 in RAW 264.7 cells. By contrast, BHSST markedly reduced the production of NO, PGE 2 , and IL- 6 in LPS-stimulated RAW 264.7 cells (Figure 4). These findings demonstrate that BHSST possesses anti-inflammatory effects by inhibiting production of $\mathrm{NO}, \mathrm{PGE}_{2}$, and IL- 6 , whereas it is not controlled by TNF- $\alpha$ production and COX- 2 expression in macrophages. Although BHSST had the inhibitory effect on $\mathrm{PGE}_{2}$ production, it did not affect COX-2 expression level. However, it may be possible that COX-2 enzymatic activity, but not expression, is involved in anti-inflammatory action of BHSST.

LPS activates the TLR4-mediated signaling pathway, and leading to the activation of NF- $\kappa \mathrm{B}$ to regulate the release of cytokines $[34,35]$. To detect the inhibitory mechanism on inflammatory action of BHSST, we carried out the effect of BHSST on TLR4 and phosphorylation of NF- $\kappa$ B. The results showed that BHSST pretreatment significantly suppressed LPS-stimulated TLR4 and NF- $\kappa$ B p 65 phosphorylation in RAW 264.7 cells (Figures 5 and 6). These finding suggested that BHSST exerts anti-inflammatory effect through the suppression of TLR4/NF- $\kappa \mathrm{B}$ pathway. It seems to be related to inhibitory effect of bioactive components of BHSST, such as baicalin [33].

Inflammatory mediators and cytokines aggravate inflammatory responses to skin lesions, which are an important feature of inflammation skin diseases such as AD [5]. Skin inflammation including $\mathrm{AD}$ develops on allergic reaction and is characterized by the overexpression of inflammatory cytokines. Furthermore, AD changed the expression of various inflammatory chemokines [36]. Chemokines are basic proteins that are secreted and critically important in allergic inflammation via leukocyte trafficking and activation. In particular, it has been reported that the serum level of RANTES, TARC, and MDC, which are Th2-type chemokines, is associated with skin inflammation $[5,6]$. Moreover, IL-8, a member of the chemokine family, is produced by various types of cells upon stimulation with inflammatory stimuli [7]. Therefore, we investigated the effect of BHSST on RANTES, TARC, MDC, and IL-8 levels in TI-stimulated HaCaT cells, and found that BHSST inhibited the production of RANTES, TARC, MDC, and IL-8 in the cells (Figure 7). These findings suggest that BHSST regulates the recruitment of Th2-type cells into inflammatory skin lesions by suppressing production of inflammatory chemokines.

IFN- $\gamma$ activates an inflammatory transcriptional program through the canonical Janus-kinase-signal transducer and activator of transcription (JAK-STAT) signaling pathway [12]. TARC production from TI-stimulated HaCaT cells is decreased by treatment with JAK/STAT inhibitors [11]. To confirm the mechanism of action of BHSST, we examined the effect of BHSST on STAT1 activation by TI stimulation in HaCaT cells. BHSST suppressed STAT1 phosphorylation and nuclear translocalization in TI-stimulated HaCaT cells (Figure 8).

In summary, our results demonstrate that BHSST exerts anti-inflammatory effects by reducing the production of NO, $\mathrm{PGE}_{2}$, and IL-6, as well as TLR4 and the phosphorylation of NF- $\kappa$ B p65 in LPS-stimulated RAW 264.7 cells. BHSST exerts suppressive effects on the production of inflammatory chemokines RANTES, TARC, MDC, and IL-8, and the phosphorylation of STAT1 in TI-stimulated HaCaT cells. Overall, these findings provide evidence that BHSST can act as a preventive and therapeutic agent for inflammationrelated skin diseases.

\section{Conflict of Interests}

All authors declare that there is no conflict of interests regarding the publication of this paper.

\section{Acknowledgment}

This research was supported by a Grant for "Construction of Scientific Evidences for Herbal Medicine Formulas (K14030)" from the Korea Institute of Oriental Medicine.

\section{References}

[1] T. K. Means, D. T. Golenbock, and M. J. Fenton, "The biology of Toll-like receptors," Cytokine \& Growth Factor Reviews, vol. 11, no. 3, pp. 219-232, 2000.

[2] I. Siddique and I. Khan, "Mechanism of regulation of Na$\mathrm{H}$ exchanger in inflammatory bowel disease: role of TLR-4 signaling mechanism," Digestive Diseases and Sciences, vol. 56, no. 6, pp. 1656-1662, 2011. 
[3] D. Damte, M. A. Reza, S.-J. Lee, W.-S. Jo, and S.-C. Park, "Antiinflammatory activity of dichloromethane extract of Auricularia auricula-judae in RAW264.7 cells," Toxicological Research, vol. 27, no. 1, pp. 11-14, 2011.

[4] N. Ahmad, L. C. Chen, M. A. Gordon, J. D. Laskin, and D. L. Laskin, "Regulation of cyclooxygenase-2 by nitric oxide in activated hepatic macrophages during acute endotoxemia," Journal of Leukocyte Biology, vol. 71, no. 6, pp. 1005-1011, 2002.

[5] D. Y. M. Leung and T. Bieber, "Atopic dermatitis," The Lancet, vol. 361, no. 9352, pp. 151-160, 2003.

[6] A. P. Kaplan, "Chemokines, chemokine receptors and allergy," International Archives of Allergy and Immunology, vol. 124, no. 4, pp. 423-431, 2001.

[7] A. Harada, N. Sekido, T. Akahoshi, T. Wada, N. Mukaida, and K. Matsushima, "Essential involvement of interleukin-8 (IL-8) in acute inflammation," Journal of Leukocyte Biology, vol. 56, no. 5, pp. 559-564, 1994.

[8] World Health Organization, WHO International Standard Terminologies on Traditional Medicine in the Western Pacific Region, WHO Library Cataloguing in Publication Data, 2007.

[9] K. G. Lee, X. Cui, and J. P. Lim, "Effect of the concurrent administration of Banhasasim-tang with cimetidine on gastric ulcer in rats," Korean Journal of Oriental Physiology \& Pathology, vol. 16, no. 3, pp. 572-576, 2002.

[10] Y. Kase, K. Saitoh, B. Makino, K. Hashimoto, A. Ishige, and Y. Komatsu, "Relationship between the antidiarrhoeal effects of Hange-Shashin-To and its active components," Phytotherapy Research, vol. 13, no. 6, pp. 468-473, 1999.

[11] S. M. Ju, H. Y. Song, S. J. Lee et al., "Suppression of thymus- and activation-regulated chemokine (TARC/CCL17) production by 1,2,3,4,6-penta-O-galloyl- $\beta$-d-glucose via blockade of NF- $\kappa \mathrm{B}$ and STAT1 activation in the HaCaT cells," Biochemical and Biophysical Research Communications, vol. 387, no. 1, pp. 115120, 2009.

[12] J. E. Darnell Jr., I. M. Kerr, and G. R. Stark, “Jak-STAT pathways and transcriptional activation in response to IFNs and other extracellular signaling proteins," Science, vol. 264, no. 5164, pp. 1415-1421, 1994.

[13] J. H. Han, S. G. Jo, M. J. Lee, S. H. Baek, and S. H. Park, “Contents of homogentisic acid and 3,4-dihydroxybenzaldehyde in the Pinellia ternate by various processing method and its safety estimate," Korean Journal of Oriental Physiology \& Pathology, vol. 18, no. 3, pp. 846-853, 2004.

[14] L. Tong, M. Wan, L. Zhang, Y. Zhu, H. Sun, and K. Bi, "Simultaneous determination of baicalin, wogonoside, baicalein, wogonin, oroxylin A and chrysin of Radix scutellariae extract in rat plasma by liquid chromatography tandem mass spectrometry," Journal of Pharmaceutical and Biomedical Analysis, vol. 70, pp. 6-12, 2012.

[15] S.-M. Shan, J.-G. Luo, F. Huang, and L.-Y. Kong, "Chemical characteristics combined with bioactivity for comprehensive evaluation of Panax ginseng C.A. Meyer in different ages and seasons based on HPLC-DAD and chemometric methods," Journal of Pharmaceutical and Biomedical Analysis, vol. 89, pp. 76-82, 2014.

[16] Q. Zhang and M. Ye, "Chemical analysis of the Chinese herbal medicine Gan-Cao (licorice)," Journal of Chromatography A, vol. 1216, no. 11, pp. 1954-1969, 2009.

[17] S. M. Zick, M. T. Ruffin, Z. Djuric, D. Normolle, and D. E. Brenner, "Quantitation of 6-, 8- and 10-gingerols and 6-shogaol in human plasma by high performance liquid chromatography with electrochemical detection," International Journal of Biomedical Science, vol. 6, no. 3, pp. 233-240, 2010.

[18] B.-L. Ma, Y.-M. Ma, R. Shi et al., "Identification of the toxic constituents in Rhizoma Coptidis," Journal of Ethnopharmacology, vol. 128, no. 2, pp. 357-364, 2010.

[19] C. Niu and J. Zhang, "Quantitative analysis and chromatographic fingerprinting of the semen zizyphi spinosae by ultrahigh-performance liquid chromatography coupled with diodearray detector," Journal of Separation Science, vol. 34, no. 21, pp. 2989-2996, 2011.

[20] M.-H. Han, X.-W. Yang, G.-Y. Zhong, and M. Zhang, "Bioactive constituents inhibiting TNF-alpha production in fresh rhizome of Pinellia ternata," Zhongguo Zhong Yao Za Zhi, vol. 32, no. 17, pp. 1755-1759, 2007.

[21] J. Kim, I. S. Lee, S. Park, and R. Choue, "Effects of Scutellariae radix and Aloe vera gel extracts on immunoglobulin $\mathrm{E}$ and cytokine levels in atopic dermatitis NC/Nga mice," Journal of Ethnopharmacology, vol. 132, no. 2, pp. 529-532, 2010.

[22] E. Cho and S. H. Cho, "Effects of Korean red ginseng extract on the prevention of atopic dermatitis and its mechanism on early lesions in a murine model," Journal of Ethnopharmacology, vol. 145, no. 1, pp. 294-302, 2013.

[23] J. P. Bak, J. H. Son, Y. M. Kim, E. Y. Lee, K. H. Leem, and E. H. Kim, "Suppression of inflammatory macrophage response by Glycyrrhiza uralensis herbal acupuncture extract," Korean Journal of Acupuncture, vol. 28, no. 4, pp. 49-58, 2011.

[24] G.-H. Guahk, S. K. Ha, H.-S. Jung et al., "Zingiber officinale protects $\mathrm{HaCaT}$ cells and $\mathrm{C} 57 \mathrm{BL} / 6$ mice from ultraviolet $\mathrm{B}$ induced inflammation," Journal of Medicinal Food, vol. 13, no. 3, pp. 673-680, 2010.

[25] J. Y. Cho, A. R. Kim, and M. H. Park, "Lignans from the rhizomes of Coptis japonica differentially act as anti-inflammatory principles," Planta Medica, vol. 67, no. 4, pp. 312-316, 2001.

[26] S. B. Acharya, M. Tripathi, and V. B. Pandey, "Antinociceptive, anti convulsant and anti inflammatory activities of Zizyphus jujube," Ancient Science of Life, vol. 14, no. 1-2, pp. 39-41, 1994.

[27] R. Goyal, P. L. Sharma, and M. Singh, "Possible attenuation of nitric oxide expression in anti-inflammatory effect of Ziziphus jujuba in rat," Journal of Natural Medicines, vol. 65, no. 3-4, pp. 514-518, 2011.

[28] T.-C. Chou, L.-P. Chang, C.-Y. Li, C.-S. Wong, and S.-P. Yang, "The antiinflammatory and analgesic effects of baicalin in carrageenan-evoked thermal hyperalgesia," Anesthesia and Analgesia, vol. 97, no. 6, pp. 1724-1729, 2003.

[29] Y.-Z. Yang, Y.-Z. Tang, and Y.-H. Liu, "Wogonoside displays anti-inflammatory effects through modulating inflammatory mediator expression using RAW264.7 cells," Journal of Ethnopharmacology, vol. 148, no. 1, pp. 271-276, 2013.

[30] M. Y. Yun, J. H. Yang, D. K. Kim et al., "Therapeutic effects of Baicalein on atopic dermatitis-like skin lesions of NC/Nga mice induced by dermatophagoides pteronyssinus," International Immunopharmacology, vol. 10, no. 9, pp. 1142-1148, 2010.

[31] B. S. Lee, S. M. Shim, J. Heo et al., "Wogonin suppresses TARC expression induced by mite antigen via heme oxygenase 1 in human keratinocytes: suppressive effect of wogonin on mite antigen-induced TARC expression," Journal of Dermatological Science, vol. 46, no. 1, pp. 31-40, 2007.

[32] Y. Fu, E. Zhou, Z. Wei et al., "Glycyrrhizin inhibits the inflammatory response in mouse mammary epithelial cells and a mouse mastitis model," FEBS Journal, vol. 281, no. 11, pp. 25432557, 2014. 
[33] L. Cui, L. Feng, Z. H. Zhang, and X. B. Jia, "The antiinflammation effect of baicalin on experimental colitis through inhibiting TLR4/NF- $\kappa \mathrm{B}$ pathway activation," International Immunopharmacology, vol. 23, no. 1, pp. 294-303, 2014.

[34] J. C. Kagan and R. Medzhitov, "Phosphoinositide-mediated adaptor recruitment controls Toll-like receptor signaling," Cell, vol. 125, no. 5, pp. 943-955, 2006.

[35] L. Ashall, C. A. Horton, D. E. Nelson et al., "Pulsatile stimulation determines timing and specificity of NF- $\kappa$ B-dependent transcription," Science, vol. 324, no. 5924, pp. 242-246, 2009.

[36] T. Imai, M. Nagira, S. Takagi et al., "Selective recruitment of CCR4-bearing $\mathrm{T}_{h} 2$ cells toward antigen-presenting cells by the CC chemokines thymus and activation-regulated chemokine and macrophage-derived chemokine," International Immunology, vol. 11, no. 1, pp. 81-88, 1999. 


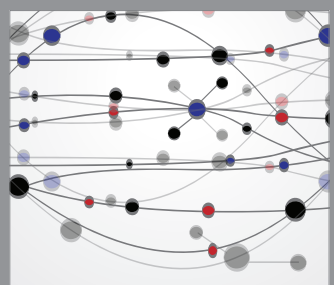

The Scientific World Journal
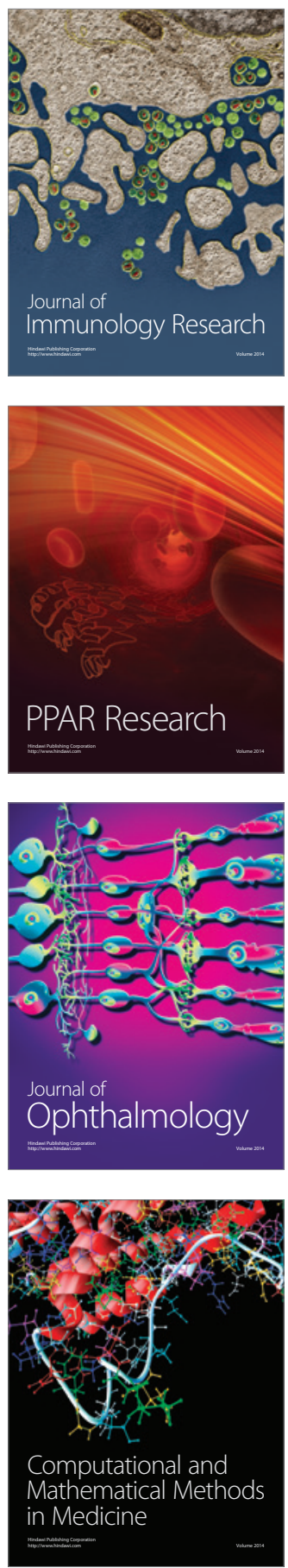

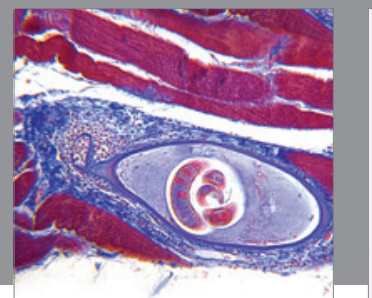

Gastroenterology

Research and Practice
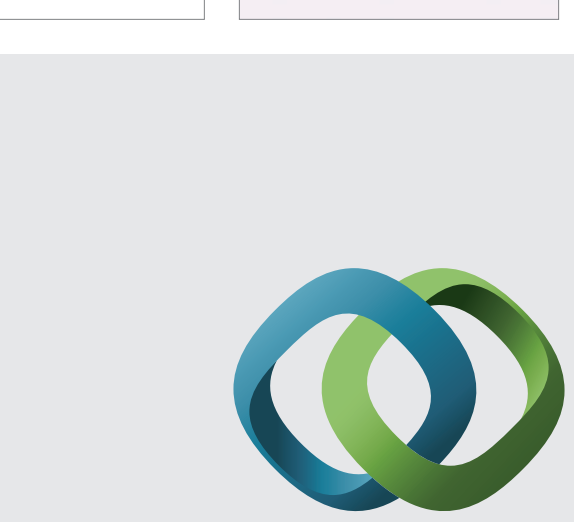

\section{Hindawi}

Submit your manuscripts at

http://www.hindawi.com
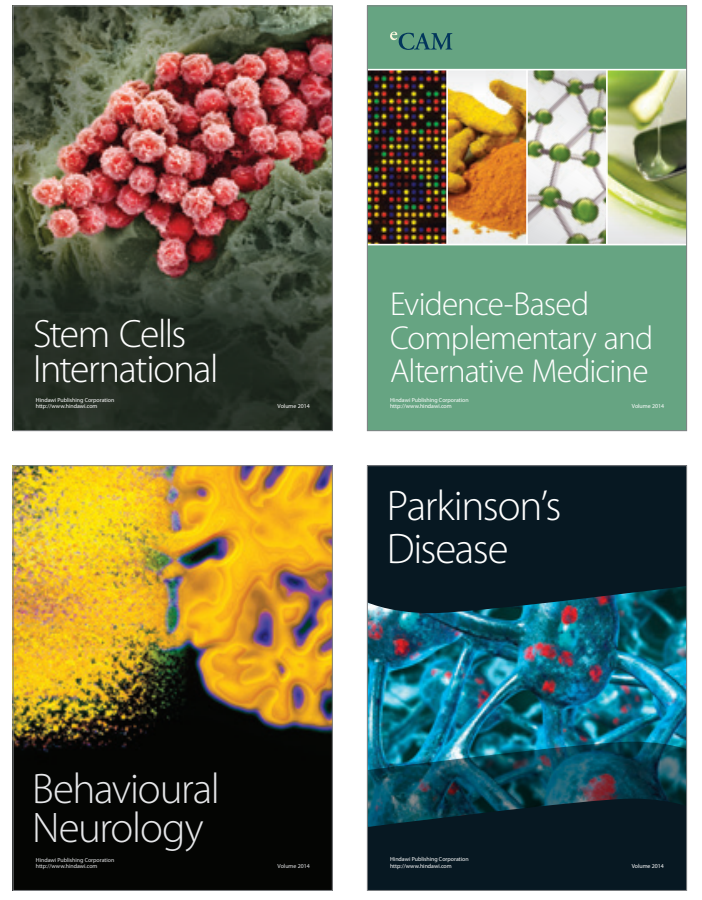
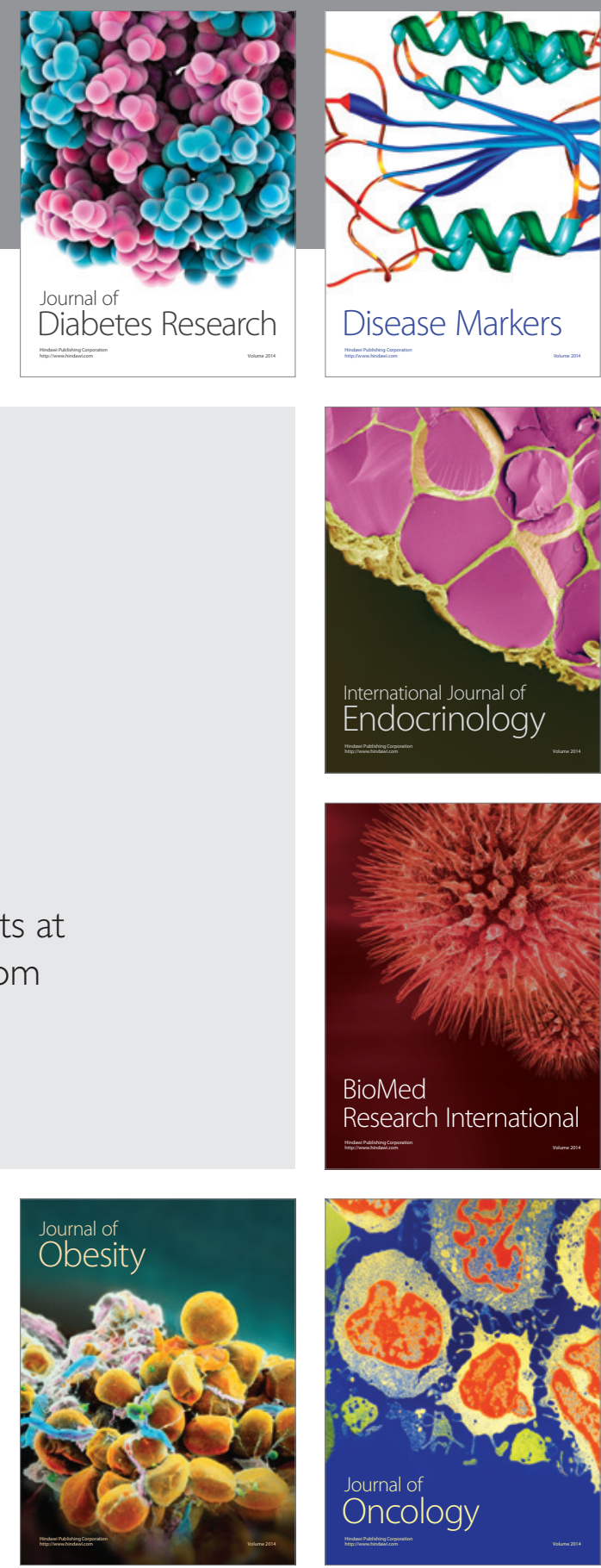

Disease Markers
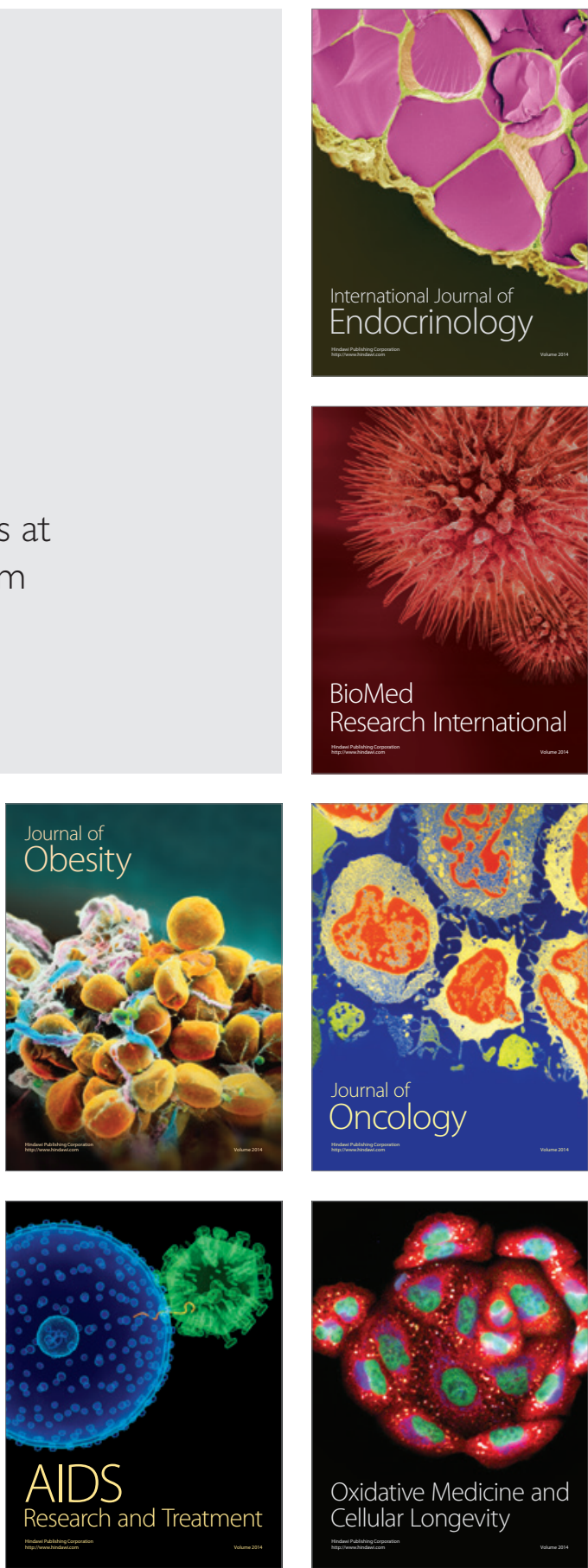